\title{
Finding a needle in a haystack of needles: The difficulty of defining a consistently meaningful cytokine signature
}

\author{
Kaitlin C. McLoughlin, MD, and R. Taylor Ripley, MD
}

\author{
From the Center for Cancer Research, National Cancer Institute, National Institutes of Health, Bethesda, Md. \\ Disclosures: Authors have nothing to disclose with regard to commercial support. \\ Received for publication Feb 25, 2018; accepted for publication Feb 28, 2018; available ahead of print April 10, \\ 2018 \\ Address for reprints: R. Taylor Ripley, MD, National Cancer Institute, Building 10; 4-3952, 10 Center Dr, MSC \\ 1201, Bethesda, MD 20892-1201 (E-mail: Taylor.Ripley@nih.gov). \\ J Thorac Cardiovasc Surg 2018;155:2646-7 \\ $0022-5223 / \$ 36.00$ \\ Copyright (c) 2018 by The American Association for Thoracic Surgery \\ https://doi.org/10.1016/j.jtcvs.2018.02.081
}

In their article in this issue of the Journal, "Genetic Variants in Cytokine Signaling Pathways and Clinical Outcomes in Early-Stage Lung Cancer Patients,' Sepesi and colleagues ${ }^{1}$ present a discovery analysis of the relationship of genomic single-nucleotide polymorphisms with cytokine signaling pathways in patients with resectable non-small cell lung cancer. The study's aim was to identify potential biomarkers for both overall and recurrence-free survivals. ${ }^{1}$ Although Sepesi and colleagues ${ }^{1}$ acknowledge limitations that prevent their study from defining predicative profiles, the study does anticipate a complex interplay of the immune system with cancer. Despite impressive responses to programmed death-ligand 1 inhibitors in non-small cell lung cancer, ${ }^{2}$ manipulating the immune system is far more intricate than immune checkpoints and their associated pharmacologic blockades. Multiple studies have demonstrated correlations between cytokine pathways and risks associated with lung cancer. These analyses have focused on both the genomic cytokine blueprint as well as on transcriptomic and proteomic landscapes. These methods pose two distinct questions about cytokines in malignancy: (1) Is there a predetermined genetic tendency toward an altered cytokine milieu associated with cancer development? (2) Is there a terminal cytokine profile in the patient with malignancy that can define outcomes? The answer to both questions is most certainly yes. Identifying a consistently influential profile will be difficult, however; cytokines are pleiotropic, are produced by multiple cell types, are released and act locally, and have very short half-lives. ${ }^{3}$

Polymorphisms have been noted in such well-known influential cytokines as tumor necrosis factor $\alpha$; transforming growth factor $\beta$; interleukins $1,6,17,8$, and 18; and (C$\mathrm{X}-\mathrm{C}$ motif) ligand. ${ }^{4}$ Some variants repeatedly demonstrate oncogenic potential even though the influential singlenucleotide polymorphism varies among studies. ${ }^{5-11}$ Many analyses fail to identify these targets as risk factors within their lung cancer cohorts, however, and therefore label their influence as "context dependent." Similarly, in the

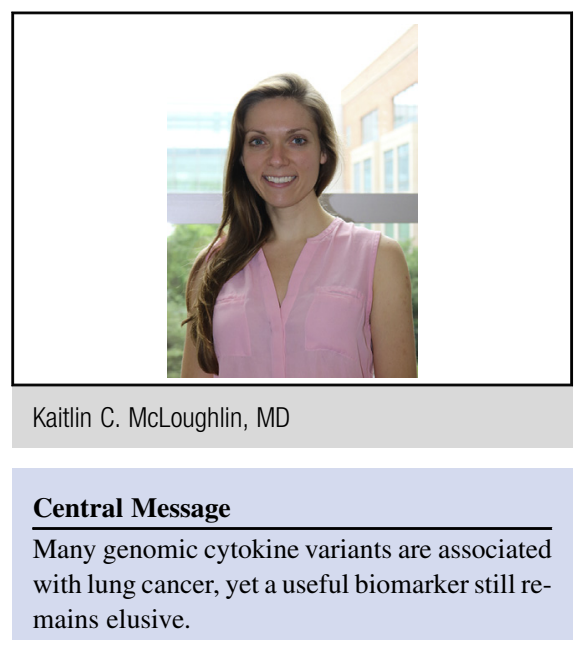

See Article page 2635.

study of Sepesi and colleagues ${ }^{1}$ many of the genetic polymorphisms found to be related to disease-free and overall survival were not among those most commonly mentioned in the literature. The analysis of Sepesi and colleagues ${ }^{1}$ has stepped beyond the evaluation of individual genes, however, by creating a profile of multiple polymorphisms in relation to survival. Sepesi and colleagues ${ }^{1}$ understandably state that cytokines act in a cumulative rather than an individual manner and contend that their overall milieu may supersede the effects any single cytokine. Their analysis also queried whether these polymorphisms predict outcomes in treated patients with cancer, in contrast to most studies, which focus on cancer initiation risk. The limitation of addressing oncogenic outcomes with genomic data is that it ignores the crucial influence of the patient's cancer on terminal cytokine expression. In most genomic studies, including that of Sepesi and colleagues, ${ }^{1}$ protein correlates have not been evaluated. Although a genetic profile may have a statistical association with oncologic risk, epigenetic, transcriptomic, proteomic, and posttranslational regulation may explain the "context dependence" of many polymorphisms. Interestingly, the analysis of Sepesi and colleagues produced 2 distinct sets of influential genes that were associated with overall and recurrence-free survivals, again pointing to the contextual influences of the immune system and cancer. In a haystack of cytokines, it is easy to find one that shows a statistical signal in the appropriate context. The difficultly lies in finding the right combination to provide consistent and reliable prediction. Despite advances in the 
field, significant work remains to establish a reliable biomarker for clinical outcomes.

\section{References}

1. Sepesi B, Ye Y, Mitchell KG, Zhang L, Gu J, Ji L, et al. Genetic variants in cytokine signaling pathways and clinical outcomes in early-stage lung cancer patients. J Thorac Cardiovasc Surg. 2018;155:2635-45.e15.

2. Marrone KA, Brahmer JR. Immune checkpoint therapy in non-small cell lung cancer. Cancer J. 2016;22:81-91.

3. Zhou X, Fragala MS, McElhaney JE, Kuchel GA. Conceptual and methodological issues relevant to cytokine and inflammatory marker measurements in clinical research. Curr Opin Clin Nutr Metab Care. 2012;13:541-7.

4. Singh DP, Bagam P, Sahoo MK, Batra S. Immune-related polymorphisms in pulmonary diseases. Toxicology. 2017;383:24-39.

5. Van Dyke AL, Cote ML, Wenzlaff AS, Chen W, Abrams J, Land S, et al. Cytokine and cytokine receptor single-nucleotide polymorphisms predict risk for non-small cell lung cancer among women. Cancer Epidemiol Biomarkers Prev. 2009;18:1829-40
6. Lind H, Zienolddiny S, Ryber D, Skaug V, Phillips DH, Haugen A. Interleukin 1 receptor antagonist gene polymorphism and risk of lung cancer: a possible interaction with polymorphisms in the interleukin 1 beta gene. Lung Cancer. 2005;50: 285-90.

7. Gao P, Zhao H, You J, Jing F, Hu Y. Association between interleukin-8 -251A/T polymorphism and risk of lung cancer: a meta-analysis. Cancer Invest. 2014;32: 518-25.

8. Kaabachi W, ben Amor A, Kaabachi S, Rafrafi A, Tizaoui K, Hamazaoui K Interleukin-17A and -17F genes polymorphisms in lung cancer. Cytokine. 2014;66:23-9.

9. Ma QY, Chen J, Wang SH, Wu N, Hao ZH, Chen XF. Interleukin 17A genetic variations and susceptibility to non-small cell lung cancer. APMIS. 2015;123: 194-8.

10. Nie W, Xue L, Sun G, Ning Y, Zhao X. Interleukin-6 -634C/G polymorphism is associated with lung cancer risk: a meta-analysis. Tumour Biol. 2014;35:4581-7.

11. Seow A, Ng DP, Choo S, Eng P, Poh WT, Ming T, et al. Joint effect of asthma/ atopy and an IL-6 gene polymorphism on lung cancer risk among lifetime non-smoking Chinese women. Carcinogenesis. 2006;27:1240-4. 